\title{
BMJ Open The effect of religion on the perception of health states among adults in the United Arab Emirates: a qualitative study
}

\author{
Iffat Elbarazi, ${ }^{1}$ Nancy J Devlin, ${ }^{2}$ Marina-Selini Katsaiti, ${ }^{3}$ \\ Emmanuel A Papadimitropoulos, ${ }^{4}$ Koonal K Shah, ${ }^{2}$ lain Blair ${ }^{1}$
}

To cite: Elbarazi I, Devlin NJ, Katsaiti M-S, et al. The effect of religion on the perception of health states among adults in the United Arab Emirates: a qualitative study. BMJ Open 2017;7:e016969. doi:10.1136/ bmjopen-2017-016969

- Prepublication history for this paper is available online. To view these files please visit the journal online (http://dx.doi org/10.1136/bmjopen-2017016969).

Received 23 March 2017 Revised 22 July 2017 Accepted 3 August 2017

\section{CrossMark}

${ }^{1}$ Institute of Public Health, College of Medicine and Health Sciences, United Arab Emirates University, Al Ain, Abu Dhabi, United Arab Emirates

${ }^{2}$ Office of HealthEconomics, London

${ }^{3}$ Department of Economicsand Finance, College of Business andEconomics, United Arab Emirates University, Al Ain, Abu Dhabi, United Arab Emirates ${ }^{4}$ Eli Lilly Canada, Toronto, Canada

Correspondence to

Dr lain Blair;

lain_Blair@uaeu.ac.ae

\section{ABSTRACT}

Objectives Investigate how religion may affect the perception of health states among adults in the United Arab Emirates and the implications for research on selfreported health and quality of life and the use of values in cost-effectiveness analysis.

Design Qualitative analysis of short-structured interviews with adult Emiratis carried out by a market research agency.The COREQ criteria have been used where appropriate to guide the reporting of our findings. Setting Participants were recruited from shopping malls and other public places in the cities of Al Ain and Abu Dhabi.

Participants Two hundred adult Emiratis broadly representative of the Emirati population in terms of age and gender.

Results Eighty one per cent of participants said that their perception of health states was influenced by their spiritual or religious beliefs. The two overarching themes that seemed to explain or classify these influences were 'fatalism' and 'preservation of life'. Subthemes included powerlessness to change what is preordained by God, fear of disability (particularly diminished mobility) and appreciation of health and life and the requirement to look after one's health. A final theme was that of acceptance, with respondents expressing a willingness to endure suffering and disability with patience in the expectation of rewards in the hereafter.

Conclusions Our results emphasise the need for further work to establish locally relevant value sets for Muslim majority countries in the Middle East and elsewhere for use in health technology assessment decision-making, rather than relying on value sets from other regions.

\section{INTRODUCTION}

Use of health-related quality-of-life (HRQOL) measures is routine in health technology assessment (HTA) and health outcomes research. Many such measures are available. The EQ-5D, a short questionnaire developed by the EuroQol Group, is widely used by HTA agencies, including the UK's National Institute for Health and Care Excellence. ${ }^{12}$ The EQ-5D was initially developed for English-speaking

\section{Strengths and limitations of this study}

- Health-related quality-of-life measures are routine in health technology assessment and health outcomes research but the health value sets on which they are based differ between countries due to social, cultural and particularly religious factors. The need for country-specific value sets is particularly important in Muslim majority countries, such as the United Arab Emirates (UAE), where the population may think differently about the trade-offs among health, length of life and death. This is one of the few studies to address these differences.

- This qualitative study involved Emirati adults living in the Emirate of Abu Dhabi (the cities of Al Ain and Abu Dhabi). However, our respondents were younger and more educated than the general Emirati population of Abu Dhabi. Also, Emiratis from the other six emirates were not included. Our finding therefore cannot be generalised to the whole of the UAE Emirati population. Also, the findings from our study cannot be applied with certainty to other Muslim Arab populations in other countries.

- The assessment of the impact of 'spiritual or religious views' on the perception of health states was limited to one open-ended question asked via a self-administered survey. This will inevitably affect the validity of our results and the strength of our conclusions.

- In a study with this design, there will be both interviewer and response bias. In addition, there is bias associated with the study design and the experience and judgement of the principal researchers when analysing and interpreting the data.

- Finally, the UAE, as a high-income Middle East country has a very specific set of social characteristics. Our findings can only be interpreted within the context of those characteristics.

populations but has since been translated so that there are now over $176 \mathrm{EQ}-5 \mathrm{D}$ language versions. ${ }^{3}$ EQ-5D describes health in terms of five dimensions (mobility, self-care, usual 
activities, pain/discomfort and anxiety/depression). The EQ-5D-3L grades each dimension on one of three levels of severity (no, some and extreme), while the newer five level variant (EQ-5D-5L) uses five levels of severity, thereby defining $\left(5^{5}=\right) 3125$ unique health states. ${ }^{4}$ In order to be used to support cost-effectiveness analyses, the EQ-5D must be accompanied by 'value sets' which summarise how good or bad each unique health state is on a scale anchored at 1 (full health) and 0 (dead). These value sets are derived by assessing the stated preferences of the general population. A variety of methods are available for this including the time trade-off (TTO), which involves asking survey respondents to evaluate health states, ${ }^{56}$ and discrete choice experiments (DCEs), which in its simplest form involves a pairwise choice between two states. Views about health may differ between countries due to social, cultural and religious factors, and so country-specific value sets are needed. ${ }^{7}$

The need for country-specific value sets is particularly important in Muslim majority countries such as the United Arab Emirates (UAE). Differences in the religious beliefs of the population will lead to very different ways of thinking about the trade-offs among health, length of life and death compared with non-Muslim countries. The UAE is unique in its health needs as well as in the medical-seeking behaviour of its people and the cultural effects on their health. ${ }^{8}$ Although EQ-5D-5L value sets have been or are currently being developed in countries such as England, Canada and China, and there is research evidence that Arabic versions of the EQ-5D-3L are valid and reliable in measuring quality of life in $\operatorname{Jordan}^{9}$ and Morocco, ${ }^{10}$ no local value sets for the EQ-5D-3L or EQ-5D-5L are available in the UAE or elsewhere in the Gulf region. ${ }^{11}$ Following calls for research on HRQOL assessment in Arabic countries, we carried out TTO and DCE valuation exercises among a sample of 200 adult Emiratis and concluded that the methods were appropriate and feasible. ${ }^{12}$ However, in that study, there was evidence of striking differences in the way that Emiratis valued health states compared with other cultural groups, namely a reluctance to consider that a health state could be 'worse than dead'. Furthermore, pain/discomfort and anxiety/depression were ranked as the least important dimensions of health, in contrast to findings in England and elsewhere. $^{713}$

To our knowledge, there have been no previous studies that have explored the influence of spiritual or religious beliefs on the perception of health states among Muslims. A study was conducted in Tunisia on TTO utilities with patients with rheumatoid arthritis but this study did not investigate the influence of religion or culture. ${ }^{14}$ Therefore, as part of our study, we explored respondents' feelings when asked to value different health states and what influence their spiritual or religious beliefs may have had on their responses. The purpose of this paper is to present the results of those additional enquiries and provide further detailed insights into (1) how spiritual or religious beliefs may affect the perception of health states among Emiratis and (2) the implications of our findings for research on self-reported health and quality of life in the region and for the use of values in cost-effectiveness analysis.

\section{METHODS}

The methods have been described previously but, in summary, interviews were conducted with adult Emiratis in Abu Dhabi and $\mathrm{Al}$ Ain. ${ }^{12}$ The target sample size was 200 respondents and data collection was carried out by Ipsos Observer, a market research agency. Participants were Emirati citizens residing in the Emirate of Abu Dhabi. Of the one million Emiratis in the UAE, about $40 \%$ live in Abu Dhabi. ${ }^{15}$ Emiratis are predominantly Arab and Muslim. It is acknowledged that our participants are not representative of all Arab Muslims or of all Emiratis. However, for simplicity, we refer to them in this paper as Emiratis. A convenience sampling approach was used, whereby members of the public were approached in shopping malls and other public places by recruiters working for Ipsos Observer. Information sheets (both in English and in Arabic) were provided and interview appointments were made for those who expressed an interest in participating. A sample that was broadly representative of the Emirati population in terms of age and gender was sought. Each respondent completed a valuation questionnaire administered within a computer-assisted personal interview in accordance with the EuroQol protocol. ${ }^{5}$ Each questionnaire comprised TTO and DCE tasks, feedback questions and an (optional) open-ended comment box. After completing the valuation questionnaire, respondents were asked further 'debrief' questions focusing on their experience of completing the valuation tasks via a self-completed survey that included closedended and open-ended questions (table 1). Participants' responses to these questions provided us with the data for the qualitative study reported here. Specifically, we used the answers to the open-ended question about the extent to which participants' answers were influenced by their spiritual or religious views in our analysis. Since we wished to investigate participants' own perspectives on the ways in which their religiosity and spirituality might influence their perception of health states, we used a descriptive, qualitative study design. Data were collected in December 2013 in Arabic and responses were later translated into English. The study was approved by the Al Ain Medical District Human Research Ethics Committee in November 2013 (no 13/82) and informed consent was obtained (using paper consent forms) from all respondents prior to their participation in the study.

\section{ANALYSIS}

Thematic analysis was used to identify themes related to the influence of spiritual or religious beliefs on the perception of health states by the respondents. ${ }^{16}$ Responses were first transcribed verbatim (by Ipsos Observer) and were 
Table 1 Further questions from which data on respondents' opinions are available

\begin{tabular}{lll}
\hline No & Question & Response type \\
\hline 1 & Was there anything in the survey that made you feel uncomfortable? & Open ended \\
2 & What did you like or dislike about the survey? & Open ended \\
3 & $\begin{array}{l}\text { Do you have any suggestions for improving the survey and making it } \\
\text { more relevant for people like you? }\end{array}$ & Open ended \\
4 & $\begin{array}{l}\text { To what extent were your answers to the questions influenced by your } \\
\text { spiritual or religious beliefs? }\end{array}$ & $\begin{array}{l}\text { Closed ended, precoded categorical } \\
\text { (0=no answer selected; } 1=\text { not influenced at all; } \\
\text { 2=somewhat influenced; 3=heavily influenced) }\end{array}$ \\
\hline 5 & Please explain how. & Open ended \\
\hline
\end{tabular}

then analysed systematically by two authors (IE and IB) working independently. The data were coded and organised into emerging themes and subthemes. Following a discussion of themes by all members of the study team, a final index was synthesised by one author (IE) acting as a content expert with detailed knowledge of Islamic faith health considerations. Direct quotes from respondents are presented where this is useful to provide additional insights or to illustrate the themes that emerged. Using an inductive approach, the emergent themes were used to make inferences about the way in which spiritual or religious beliefs will affect the perception of health states. The study reported here was part of a pilot study, the primary purpose of which was to investigate the feasibility and cultural appropriateness of stated preference methods to generate EQ-5D-5L values in the UAE. The target sample size for this pilot study was 200 and this provided 88 completed interviews for the qualitative element of the study. This figure is pragmatic rather that theoretical but in the authors' opinion will provide data of sufficient quality and quality to provide for data saturation. Indeed the final finite themes emerged promptly during the data analysis.

\section{RESULTS}

As previously reported, ${ }^{12}$ the final sample comprised 200 respondents and complete background demographic data were available for 166 of these. Background data are unavailable for the remaining 34 respondents due to a recording error but it is not expected that the missing respondents will differ systematically from the rest of the sample. In their answers to open-ended question nos $1-3$, some participants mentioned that they disliked the sensitive nature of the questions or took issue with fundamental aspects of the valuation methods, for example, choosing to give up time or having to choose between two health states. Others reported feeling uncomfortable with the questions such as the idea of imagining living with some disability or other condition and thinking about illness and death. However, one participant stated: "Living in a wheelchair and living with severe problems moved me because in our religion we believe in fate". Others indicated that they liked the questionnaire because it made them reflect on their current life and made them appreciate health and life being a precious gift and an Amana (meaning in English: something to be trusted and protected) from God that one should protect: "I liked the survey because it made me think about the gifts I have". Among the 116 respondents who answered the question 'To what extent were your answers affected by your spiritual or religious beliefs', 22 (19\%) replied 'not influenced at all', $60(51 \%)$ replied 'somewhat influenced' and $34(30 \%)$ replied 'heavily influenced'. Of the 94 respondents who said that they were 'somewhat, or heavily influenced', 88 provided an answer to open-ended question no 5. Their characteristics are summarised in table 2. Older and less-educated individuals are under-represented in our sample, though it should be noted that the Emirati population of Abu Dhabi is very youthful, with a median age of approximately 19 years. ${ }^{17}$ The population is also relatively well educated: in a recent study involving a random sample of Emirati households, $29 \%$ of heads of household were educated to college or postgraduate level. ${ }^{18}$ All of the respondents were Muslim. Participants' responses in general were short and did not require detailed interpretation. From the 88 responses to question no 5, 146 themes were discerned. The recurring themes were apparent very clearly and were classified into two major categories each with three subthemes (table 3). These are discussed in turn in the following section.

\section{Theme 1: fatalism}

Under the concept of fatalism, we identified three subthemes. First, the subtheme of inevitability and invincibility which strongly emphasised how individual life conditions heavily depend on God and are thus inevitable. Several individual statements express this belief, examples of which are the following: 'I believe in destiny and everything is in the hands of God', 'because we believe that destiny is set by God'. The second subtheme is the concept of powerlessness, helplessness or submission. Respondents stated their powerlessness and helplessness with respect to their health condition and that they can only submit to God and accept his will. The following statements are examples of these beliefs: 'Because destiny is preordained by God and it is impossible to imagine death or life and illness' and 'Because these questions are related to the power of God, He who grants and assists'. Many participants used quotes from the prophet 


\begin{tabular}{|c|c|c|}
\hline Characteristic & $\mathbf{n}$ & $\%$ \\
\hline Total & 88 & 100.0 \\
\hline \multicolumn{3}{|l|}{ Gender } \\
\hline Male & 43 & 48.9 \\
\hline Female & 45 & 51.10 \\
\hline \multicolumn{3}{|l|}{ Age group (years) } \\
\hline Under 30 & 18 & 20.58 \\
\hline $30-39$ & 44 & 50.0 \\
\hline $40-49$ & 18 & 20.5 \\
\hline 50 and over & 7 & 7.9 \\
\hline No answer given & 1 & 1.1 \\
\hline \multicolumn{3}{|l|}{ Marital status } \\
\hline Single & 31 & 35.2 \\
\hline Married & 51 & 58.0 \\
\hline Divorced or widowed & 2 & 2.3 \\
\hline No answer given & 4 & 4.5 \\
\hline \multicolumn{3}{|l|}{ Employment status } \\
\hline Home maker/housewife & 21 & 23.9 \\
\hline Retired/student/not working & 13 & 14.8 \\
\hline Working part time & 14 & 15.9 \\
\hline Working full time & 32 & 36.4 \\
\hline No answer given & 8 & 9.1 \\
\hline \multicolumn{3}{|l|}{ Education } \\
\hline No education & 6 & 6.8 \\
\hline Schooling but no university & 5 & 5.7 \\
\hline Current university student & 14 & 15.9 \\
\hline Graduate & 58 & 65.9 \\
\hline No answer given & 5 & 5.7 \\
\hline
\end{tabular}

Percentages do not always sum to $100 \%$ because of missing values and rounding.

of Islam (Muhammad) that indicate that life and death are in God's hands. Some participants also used some of the known names or characteristics of God (Allah) in their replies namely 'The All Powerful (ردداقل)' and 'The Creator of All Power (ردتقملا)'. These two names or description of Allah are usually known to be among the 99 names of Allah referred to in the Quran. Also the word or the name of 'the One who cures and heals' was also quoted by many of the participants (يفاشلا) referring to the belief that it is Allah who cures all ailments which is also taken from the reported sayings of the prophet. The third 'fatalism' subtheme was the 'unacceptability of certain ideas'. Participants highlighted in their answers the unacceptability of (1) choosing between death and illness and (2) consciously avoiding death, which is in God's power. Some respondents who felt that the survey made them uncomfortable mentioned the following reasons: 'I was always trying not to choose death', 'Many questions made me feel uncomfortable, especially when you have to choose between death and living with a chronic disease'.

\section{Theme 2: preservation of life}

Under this second main theme, we also identified three subthemes: appreciation, fear and acceptance and patience. Respondents made comments expressing appreciation for their life and health, noting that the questions had reminded them to be more religious. The TTO and the DCE exercises reminded the respondents of how important good health is, and made them express their gratitude to God for granting them good health. It also made them appreciate health in general. Examples were: 'Health is the most important blessing that the Lord has granted us', 'I was touched by the fact that some people suffer from many diseases and that's why I thank God for my good health', 'Life is beautiful and we should preserve it and preserve our health in order to enjoy its beauty'. Participants appeared to have a fear of disability and diminished mobility since in the ranking exercise, they ranked mobility as the most important aspect of health. The concept of punishment for bad actions in life as being one of the causes of illness, disability and death also appeared in participants' responses: 'I remembered the existence of the day of reckoning after death', 'Because illness is in the hands of God the Great and Almighty; He is the one who punishes us or helps us'. Respondents also revealed acceptance and patience in the way they view life. These are discernible elements in the Muslim religion and become fundamental components when faced with life challenges. Examples of this final subtheme are: 'There is no $100 \%$ healthy life but one has to live with the illness anyway' and 'We live life in its good and bad'.

\section{DISCUSSION}

This study has shown that spiritual or religious beliefs have an important effect on the way that Emiratis think and respond to the stated preference tasks commonly used to value health states. We found that the responses of over three quarters of respondents were influenced by their spiritual or religious views. Although our study used only the EQ-5D, the factors outlined in this paper are likely to effect the valuation of other HRQOL measures. ${ }^{19}$ In our study, fatalism and preservation of life were the two overarching concepts that influenced participants' perception of health states. Our results are comparable with other findings reported in the literature on the role of religion in health valuations, behaviours and outcomes. ${ }^{19} 20$ For example, in the study by Gowani, a conceptual framework of factors affecting non-communicable disease preventive behaviours is proposed including fatalism, invincibility and fear of premature death. In agreement with these results, our respondents also referred to the concept of destiny and their belief that health, life and death are in God's hands. In contrast, Rassool discusses Muslims' belief of acceptance rather than fatalism, as for Muslims, suffering and dying are considered a test from Allah: 'Be sure we shall test you 
Table 3 Themes and subthemes apparent from analysis of respondents' comments

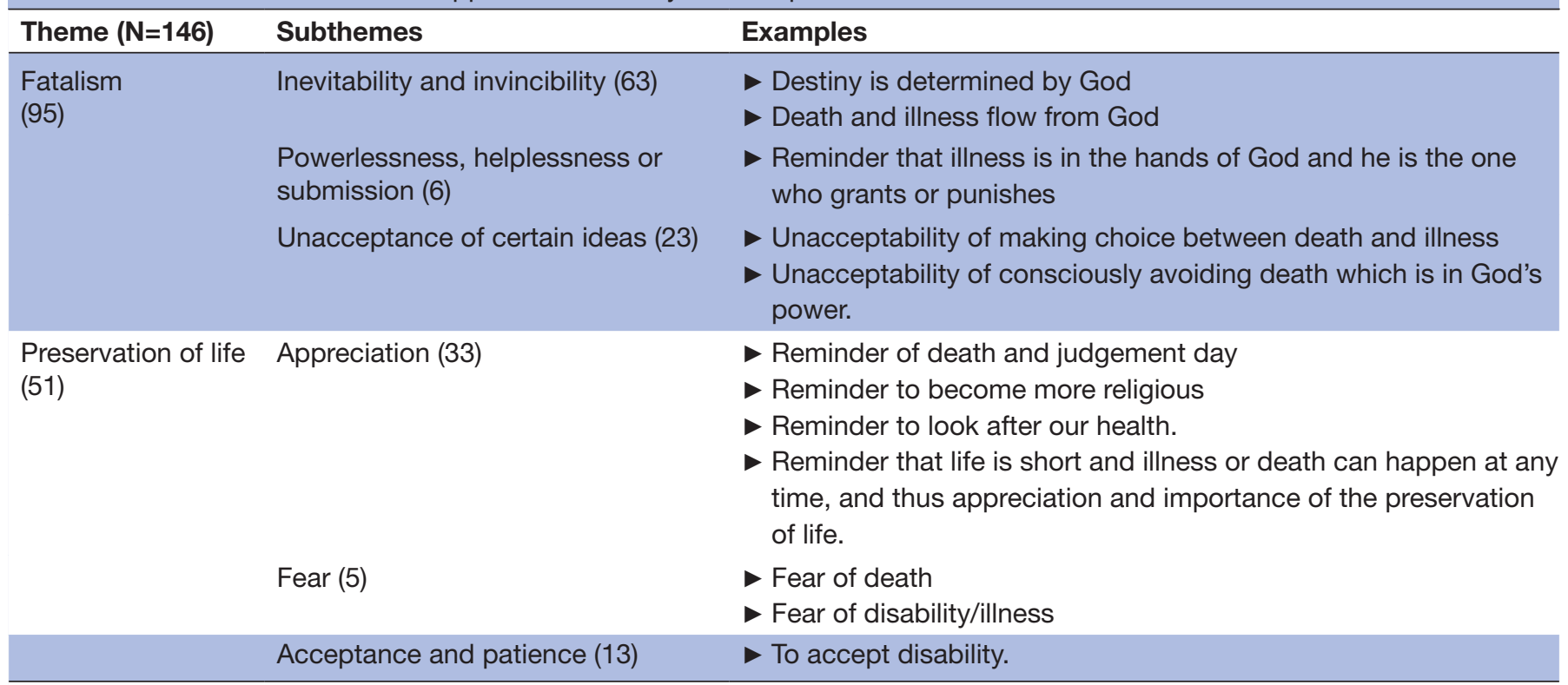

Numbers in parentheses are the number of responses that were classified according to each category.

with something of fear, hunger, some loss In wealth, lives or the produce, but give glad tidings to those who patiently persevere (Al-Baqarah 2:155) ${ }^{21}$ Acceptance and patience was a prominent theme in our study, suggesting that Emiratis might be more submissive and accepting of the idea of death and illness. In earlier studies, Athar had explained that illness, for Muslims, is an atonement for their sins and will help them meet God cleansed of their sins. ${ }^{22}{ }^{23}$ This was also a theme that featured in our study. Participants in the Gowani study perceived themselves to be invincible and lacking any great appreciation of the threats to their health and in agreement with our study they referred to preordained fate as the main factor influencing health and illness. However, in contrast to our study, Gowani does not mention the role of God in people's lives. Both studies identify a fear of premature death but while in the Gowani study, fear of death appears to be an instrument toward preventive and self-care behaviours, in our study it is seen as a reminder to value and preserve health as a gift from God.

Our study has a number of limitations. Our respondents were younger and more educated than the general Emirati population of Abu Dhabi and Emiratis from the other six emirates were not included so our finding therefore cannot be generalised to the whole of the UAE Emirati population. Also the findings from our study cannot be applied with certainty to other Muslim Arab populations in other countries. The assessment of the impact of 'spiritual or religious views' on the perception of health states was limited to one open-ended question asked via a self-administered survey. This will inevitably affect the validity of our results and the strength of our conclusions. In a study with this design, there will be both interviewer and response bias and bias associated with the study design and the experience and judgement of the principal researchers when analysing and interpreting the data. Finally, the UAE, as a high-income
Middle East country has a very specific set of social characteristics. Our findings can only be interpreted within the context of those characteristics.

Our study captured responses to two stated preference tasks, TTO and DCE. Some of the concepts identified relate to both tasks (eg, concept of appreciation and concept of acceptance and patience) and would apply equally to other approaches that are used for valuing HRQOL (eg, visual analogue scale and standard gamble). Other concepts and issues (eg, concept of fear, rejection of the idea of trading time) appeared to be more specific to the trade-offs required in TTO than to the DCE tasks but would be equally pertinent to variants of the DCE involving duration, and in some cases to the standard gamble. Nevertheless, our earlier study demonstrated that it is feasible and culturally appropriate to carry out studies and derive value sets in Muslim Arab populations using existing methodologies. However, there are a number of ways in which the methods could be adapted for use in these populations, such as an increased emphasis in the instructions that the tasks are not intended to cause conflict with respondents' spiritual or religious beliefs.

Our study has shown that religious and spiritual beliefs will influence the values generated from health preference exercises and their use in cost-effectiveness analyses among Emiratis. Specifically health states involving disability may be given lower values than those involving pain and anxiety and depression. Also, overall HRQOL scores among Emiratis may be higher than those in other populations because an aversion to contemplating health states as 'worse than death'. These factors will have an important effect on efforts to develop value sets for HRQOL measures. Understanding the effect of spiritual or religious beliefs on respondents' reactions to valuation tasks 
will be important in adapting the valuation methods that are currently in use. In the following section, we detail aspects of the Islamic faith likely to be of particular importance in this respect.

\section{Islamic beliefs and their influence on health state perception}

There are many teachings that influence the views of Muslims about health, illness and dying. Muslims believe in the absolute timeless knowledge of God (Al Qadaa wal Qadar), fate and destiny, and the supreme power of God over human life. Belief in fate and destiny are also fundamental beliefs of the Islamic faith. On the other hand, Islam teaches that Muslims have choice over their actions and that they should protect their health and preserve their lives. The teachings of the Prophet Muhammad describe the preservation of life and health as being an act of worship and being highly praised by God. ${ }^{24}$ The Quran encourages Muslims to accept illness, suffering and dying with patience. ${ }^{21}$ Moreover, Islam teaches that calamities can absolve the sins of a pious Muslim. These concepts can influence Muslims' perception of dying and illness and their preferences over different health outcomes. Muslims are strongly encouraged to seek treatment and care and are discouraged from pursuing illness. ${ }^{21}$ However, some Muslims misunderstand this concept and may choose to ignore seeking treatment and preventive measures in the belief that they are submitting to their fate and destiny. ${ }^{25}$ Ahmad and Harrison argue that religion continues to be defined as a cultural identity which influences knowledge, attitude and practice including health beliefs and behaviours. ${ }^{26}$ Therefore, it is important to remember that health promotion programme and efforts to improve health should remain cognizant of cultural and religious beliefs particularly within Islamic communities. Our study reinforces this principle and also points to the importance of spiritual or religious beliefs in other areas of public health activity including perception of health states and HTA. Ahmad and Harrison also discuss the concept of fear as being a motivation for health-related actions. They hypothesise that religion may increase responsiveness to fear-arousing messages that will lead eventually to lower health risks. Clearly, religion influences morality, ideology and decision-making ${ }^{27}$ and the concept of fear among Muslims has been recommended by some researchers to be used and integrated in health promotion models designed for Muslim communities. ${ }^{192528}$ The notion of acceptance, submission, fatalism and inevitability lead Muslims to value health as being a gift from God and endure suffering and disability with patience and acceptance in expectation of better rewards in the hereafter. Researchers must be aware of all of these aspects of spiritual and religious beliefs that will influence perception of health states in Muslim populations.

\section{CONCLUSIONS}

Our results emphasise the importance of further work to establish locally relevant value sets for the Middle East for use in HTA decision-making, rather than relying on value sets from other regions. We also recommend further exploration of how people in the UAE and other, predominantly, Muslim countries interpret the concept of worse than dead health states, and whether alternatives to TTO may be more appropriate for these populations.

Contributors NJD, KKS and EAP designed the study. KKS, EAP and IE analysed and interpreted the data with input from NJD and M-SK. IB and IE wrote the first draft. IB is the guarantor. All authors revised it critically for important intellectual content and approved the final version for publication. All authors agree to be accountable for all aspects of the work.

Funding This study was funded by an unrestricted research grant by Eli Lilly and Company.

Competing interests EAP is an employee of Eli Lilly and Company.

Ethics approval The study was approved by the Al Ain Medical District Human Research Ethics Committee in November 2013, no 13/82.

Provenance and peer review Not commissioned; externally peer reviewed.

Data sharing statement № additional data are available.

Open Access This is an Open Access article distributed in accordance with the Creative Commons Attribution Non Commercial (CC BY-NC 4.0) license, which permits others to distribute, remix, adapt, build upon this work non-commercially, and license their derivative works on different terms, provided the original work is properly cited and the use is non-commercial. See: http://creativecommons.org/ licenses/by-nc/4.0/

(c) Article author(s) (or their employer(s) unless otherwise stated in the text of the article) 2017. All rights reserved. No commercial use is permitted unless otherwise expressly granted.

\section{REFERENCES}

1. Kind P, Brooks R, Rabin R. EQ-5D concepts and methods: a developmental history. Dordrecht: Springer, 2005.

2. National Institute for Health and Care Excellence. Guide to the methods of technology appraisal 2013. London: National Institute for Health and Care Excellence, 2013.

3. Devlin N, Brooks R. EQ-5D: past, present, future. Appl Health Econ Health Policy 2017.

4. Herdman M, Gudex C, Lloyd A, et al. Development and preliminary testing of the new five-level version of EQ-5D (EQ-5D-5L). Qual Life Res 2011;20:1727-36.

5. Oppe M, Devlin NJ, van Hout B, et al. A program of methodological research to arrive at the new international EQ-5D-5L valuation protocol. Value Health 2014;17:445-53.

6. Gold MR, Siegel JE, Russell LB, et al. Cost-effectiveness in health and medicine. New York: Oxford University Press; 1996.

7. Szende A, Oppe M, Devlin N. EQ-5D valuation sets: an inventory, comparative review and users' guide. Dordrecht: Springer, 2007.

8. Sheikh Saud bin Saqr Al Qasimi Foundation for Policy Research. Fact Sheet: Public Health in the United Arab Emirates and Ras Al Khaimah. Ras Al Khaimah: Sheikh Saud bin Saqr Al Qasimi Foundation for Policy Research, 2015. http://www. alqasimifoundation.com/admin/Content/File-1312201511130.pdf/9 (accessed 28 Jan 2017).

9. Aburuz S, Bulatova N, Twalbeh M, et al. The validity and reliability of the Arabic version of the EQ-5D: a study from Jordan. Ann Saudi Med 2009;29:304-8.

10. Khoudri I, Belayachi J, Dendane T, et al. Measuring quality of life after intensive care using the Arabic version for Morocco of the EuroQol 5 dimensions. BMC Res Notes 2012;5:56.

11. EuroQol Research Foundation. EQ-5D-3L value sets. http://www. euroqol.org/about-eq-5d/valuation-of-eq-5d/eq-5d-3l-value-sets. html (accessed 19 Dec 2014).

12. Papadimitropoulos EA, Elbarazi I, Blair I, et al. An Investigation of the feasibility and cultural appropriateness of stated preference methods to generate health state values in the United Arab Emirates. Value Health Reg Issues 2015;7:34-41.

13. Devlin $\mathrm{N}$, Shah $\mathrm{K}$, Feng $\mathrm{Y}$, et al. Valuing health related quality of life: An EQ-5D-5L value set for England. Research Paper 16/01. London: Office of Health Economics 2016. 
14. Bejia I, Salem KB, Touzi M, et al. Measuring utilities by the time trade-off method in Tunisian rheumatoid arthritis patients Clin Rheumatol. 2006;25:38.

15. Federal Competitiveness and Statistics Authority. UAE in Figures 2014. Dubai: Federal Competitiveness and Statistics Authority, 2015. http://old.fcsa.gov.ae/EnglishHome/ReportDetailsEnglish/tabid/121/ Default.aspx?ltemld=2442\&PTID=187\&Menuld=2 (accessed 30 May 2017).

16. Bazeley P, Jackson K. Qualitative Data Analysis with NVivo. 2nd ed. London: SAGE Publications Ltd, 2013:193-4.

17. Statistics Center Abu Dhabi. Statistical Yearbook of Abu Dhabi 2016. Abu Dhabi: Statistics Center Abu Dhabi. 2016 https://www. scad.ae/en/Pages/ThemeReleaseDetail.aspx?ReleaselD=819\& ThemelD=1 (accessed 4 June 2017).

18. Yeatts $\mathrm{KB}$, El-Sadig M, Leith $\mathrm{D}$, et al. Indoor air pollutants and health in the United Arab Emirates. Environ Health Perspect 2012;120:687-94.

19. Gowani A, Ahmed HI, Khalid W, et al. Facilitators and barriers to NCD prevention in Pakistanis-invincibility or inevitability: a qualitative research study. BMC Res Notes 2016;9:282.

20. Ong WM, Chua SS, Ng CJ. Barriers and facilitators to self-monitoring of blood glucose in people with type 2 diabetes using insulin: a qualitative study. Patient Prefer Adherence 2014;8:237-46.
21. Rassool GH. The crescent and Islam: healing, nursing and the spiritual dimension. Some considerations towards an understanding of the Islamic perspectives on caring. J Adv Nurs 2000;32:1476-84.

22. Athar S. Islamic Perspectives in Medicine. A Survey of Islamic Medicine: Achievements and Contemporary Issues American Trust Publications, Indianapolis. 1993.

23. Athar S. Information for health care providers when dealing with a Muslim patient. Illinois: Islamic Medical Association of North America, 1998:1-3.

24. Khayat O. Health: an Islamic perspective. The Right Path to Health: Health Education through Religion. Alexandria: World Health Organization, 1997.

25. Elbarazi I. Exploring the Use of Religious Health Promoting Messages in Australia: an Islamic Perspective. (Master Thesis). Melbourne La Trobe University, 2005

26. Ahmad K, Harrison J. Untapped Potential: Cultural SensitivityIslamic Persuasive Communication in Health Promotion Programs. Paper presented at the Global Communication and Development Conference Shanghai. 2007.

27. Pinter B, Hakim M, Seidman DS, et al. Religion and family planning. Eur J Contracept Reprod Health Care 2016;21:486-95.

28. De Leeuw E. Islamic health promotion and interculturalization. Health Promot Int 1999;14:347-53. 